\title{
Comparative Study of Electrode Wear Estimation in Wire EDM using Multiple Regression Analysis and Group Method Data Handling Technique for EN-8 and EN-19
}

\author{
G. Ugrasen, H.V. Ravindra, G.V. Naveen Prakash and D.L. Vinay
}

\begin{abstract}
Wire Electrical Discharge Machining (WEDM) is a specialized thermal machining process capable of accurately machining parts with varying hardness or complex shapes, which have sharp edges that are very difficult to be machined by the main stream machining processes. In WEDM a specific wire run-off speed is applied to compensate wear and avoid wire breakage. Since the workpiece generally stays stationary and short discharge durations are applied, the relative displacement between wire and workpiece during one single discharge is very small. This study outlines the development of model and its application to optimize WEDM machining parameters using the Taguchi's technique which is based on the robust design. Present study outlines the electrode wear estimation in the wire EDM. EN-8 and EN-19 was machined using different process parameters based on $L^{\prime}{ }_{16}$ orthogonal array. Among different process parameters voltage and flush rate were kept constant. Parameters such as bed speed, current, pulse-on and pulse-off was varied. Molybdenum wire having diameter of $0.18 \mathrm{~mm}$ was used as an electrode. Electrode wear was measured using universal measuring machine. Estimation and comparison of electrode wear was done using multiple regression analysis and group method data handling technique. From the results it was observed that, measured electrode wear and estimated electrode wear correlates well with respect to MRA than GMDH.
\end{abstract}

Keywords--- Group Method Data Handling Technique (GMDH), Multiple Regression Analysis (MRA), Wear and WEDM

\section{INTRODUCTION}

$\mathrm{W}$ IRE Electrical Discharge Machining (WEDM) is a specialized thermal machining process capable of

G. Ugrasen, Assistant Professor, Mechanical Engineering, BMS College of Engineering, Bangalore, India. E-mail:ugrasen.g@gmail.com

H.V. Ravindra, Professor, Mechanical Engineering, PES College of Engineering, Mandya, India. E-mail:mailhovera@yahoo.com

G.V. Naveen Prakash, Professor, Mechanical Engineering Vidya Vardhaka College of Engineering, Mysore, India.E-mail:npgvi@yahoo.co.in

D.L. Vinay, Assistant Professor, Mechanical Engineering, Dayanada Sagar Academy of Technology \& Management, Bangalore, India. E-mail: vinaydl.viny@gmail.com

DOI : 10.9756/BIJIEMS.6022 accurately machining parts of hard materials with complex shapes.

WEDM has evolved as a simple means of making tools and dies to the best alternative of producing micro-scale parts with the highest degree of dimensional accuracy and surface finish. Molybdenum wire is used in limited applications which require very high tensile strength to provide a reasonable load carrying capacity in small diameter wire. The effect of process parameters on the electrode wear and the amount of the erosion on wire is to be investigated experimentally in wire EDM. An attempt has been made to estimate wire wear out using multiple regression analysis and group method data handling technique. In the past, many researchers have investigated the effects of process parameters on workpiece in WEDM.

A strip EDM to overcome the wire breakage due to overheating electrodes in EDM turning process was proposed. The machining speed and surface roughness increased as the peak current increased due to high discharge energy. An increase in radial depth of cut resulted in lower MRR because the machining area increased and the flushing effect decreased. Unlike wire-EDM turning, the strip-EDM method did not result in a broken-electrode problem or cusps on the machined surface. In addition, the surface roughness was also smoother [1]. The influence of relative speed in WEDM was assessed. Wire electrical discharge dressing uses relative speeds that are typically not found in other EDM applications. The material removal was found to increase as relative speeds are increased. They have recommended that the high relative speeds are strongly recommended in electrical discharge dressing, helping to make this process feasible for on-machine conditioning metal bonded diamond wheels [2]. The characteristics of surface integrity v/s discharge energy in WEDM of Inconel 718 were studied. Surface topography by main cut and rough trim cut at high discharge energy show coral reef microstructures with few voids, while random micro voids are dominant characteristics on the EDMed surfaces by trim cuts at low discharge energy. Roughness was significantly reduced from $3.75 \mu \mathrm{m}$ to $1.25 \mu \mathrm{m}$ at low discharge energy [3]. A new EDM method using a strip electrode (strip EDM) to reduce the tool-electrode wear in EDM process was developed. Strip EDM uses a continuously applied strip electrode similar to the wire electrode in wire EDM. In the suggested strip electrode method, a conductive strip moves on the electrode guide. The worn strip is removed, and a new one 
is supplied continuously. Therefore, the tool electrode acquires no wear during the machining process. This method uses a conductive strip that is made of brass. In the practical machining process, the strip EDM method was applied to EDM milling and EDM turning and their machining characteristics were compared with general EDM methods. In the EDM milling process, the general method using a block electrode caused a shape error due to electrode wear during machining, but the strip-EDM milling did not present this problem. In the case of strip-EDM turning, the flat electrode did not produce a cusp, and the large area of the strip increased the MRR [4]. The application of micro wire Electrical Discharge Machining (micro wire-EDM) for profile roughs and final dressing of Polycrystalline Diamond (PCD) wheels using a specific pulse generator were proposed. The pulse generator using anti-electrolysis circuitry and digital signal processor based pulse control circuit was developed to suppress damages on the machined surface of PCD while achieving stable machining. By applying a specific pulse generator, a PCD wheel with a grinding-edge thickness of $3 \mu \mathrm{m}$ has been successfully fabricated by micro wire-EDM [5].

The EDM behaviors of SiC were investigated and foil electrodes were employed to slice the $\mathrm{SiC}$ ingot. The EDM machining performances of $\mathrm{SiC}$ are experimentally studied and compared to that of steel. The foil EDM of SiC is feasible and the cutting kerf loss is acceptable. Negative polarity is more suitable for foil EDM of $\mathrm{SiC}$ with higher machining speed and lower tool wear ratio under short pulse duration. The cutting speed of foil EDM of $\mathrm{SiC}$ can be improved by increasing the discharge current and using thinner foil electrode. Under the same preset machining conditions, the tool wear ratio of $\mathrm{EDM}$ of $\mathrm{SiC}$ is much lower compared to that of steel. Also the material removal rate of $\mathrm{EDM}$ of $\mathrm{SiC}$ is much higher than that of steel. Thermal cracks caused by thermal stress are considered to be one main mechanism of the removal of the material in EDM process of $\mathrm{SiC}$ [6]. A new type of EDM, WED milling, that uses a wire guide with reciprocating rotation were developed. In this method a wire guide with a hemisphere tip is used. After carrying out the machining tests for basic shapes and for some advanced applications, the feasibility of this method in 3D cavity production was confirmed. By this method, 3D machining similar to the mechanical milling with a ball end mill is realized. This method is free from the problems such as tool wear or the built-up edge in mechanical milling. The new method, when applied in conjunction with the numerical control system, is expected to become a powerful tool for machining 3D cavities with high precision [7]. The MicroEDM equipment for drilling the spray holes of diesel injector nozzles with high emission standard were designed and developed. The study focused on the mechanism design of multifunction electrode feed head and the process control of numbers of holes in a batch processing. The electrode feed head integrated the macro/micro feed axes, the piezoelectric actuator, the dual clamps and the original Taper-Swinging Mechanism (TSM), so the composite functions for wire electrode are achieved including the guider positioning, the servo feed, the inchworm feed for wear compensation, and the taper-swing movement. The developed equipment has been applied in the machining of spray holes of diesel injector nozzles. Compared with the machining efficiency of straight hole without assisted vibration that of taper hole with assisted vibration was improved by $44 \%$, and the machining-feed efficiency of each hole was up to $1.5 \mathrm{~mm} / \mathrm{min}$ without including the auxiliary time [8]. A new compensation method Based on the Scanned Area (BSA) in each layer machining was proposed. The new method is integrated with a $\mathrm{CAD} / \mathrm{CAM}$ system to generate 3D micro cavities. Experimental results have been compared with those using the Uniform Wear Method (UWM) and those using a combination of linear compensation with UWM. Experimental results indicate that MRR of the proposed method increases and TWR decreases because the electrode wear length is evenly distributed in one layer machining, which reduces the occurrence of abnormal discharges. It was found that using the proposed method machining efficiency was improved and tool wear ratio was reduced [9]. The super-finished surfaces using meso-micro EDM were studied. Super-finished surfaces having $\mathrm{Ra}<0.06 \mu \mathrm{m}$ have been generated using die sinking EDM in meso-micro scale using a novel stochastic orbiting strategy and a low stray capacitance power circuit. The stochastic orbiting strategy reduces the pre-polishing requirement of the tool electrode. Surface defects such as in homogeneity, cracks and arc spots have been analyzed and minimized, aiding both the aesthetic and functional aspects of the machined surfaces. Due to the absence of dielectric additives and small machining gap widths, sub-micro meter accuracy can be achieved for the machined features. For the same erosion times, reduction in pre-polishing of the electrode delivers higher energy and economic efficiency in die sinking EDM to machine free-form super-finished surfaces in mesomicro scale [10].

The analysis and optimization of micro-geometry parameters (i.e. total profile deviation ' $\mathrm{F}_{\mathrm{a}}$ ' and accumulated pitch deviation ' $F_{p}$ ') of the Wire Electric Discharge Machined (WEDMed) fine-pitch miniature spur gears made of brass were discussed. Effects of four WEDM process parameters namely voltage, pulse-on time, pulse-off time and wire feed rate on the micro-geometry of the miniature gears were analyzed by conducting the experiments designed using BoxBehnken approach of Response Surface Methodology (RSM). Analysis of variance study found all four input parameters significant. Larger deviations in profile and pitch were observed with higher values of the voltage and pulse-on time, and with lower values of wire feed rate and pulse-off time. Multi-performance optimization of WEDM parameters was done using the desirability analysis to minimize profile deviation and pitch deviation simultaneously [11]. An overview of the EDM process, modeling of process parameters, and influence of process parameters such as input electrical variables, pulse shape, and discharge energy on performance measures such as material removal rate, surface roughness and electrode wear rate was discussed. This study also discusses about controlling the electrical process parameters, and empirical relationships between process parameters and optimization of process parameters in EDM process. From the review results, it has been observed that the efficacy of the machining process can be improved by 
electrical process parameters, and only less attention has been given for enhancing such parameters [12]. A wire tool electrode in travelling from a supply reel to take up reel; due to the electrical discharges developed between the tool electrode and the workpiece, parts having various contours could be detached from a plate workpiece were found. In order to improve the machining process efficiency, various solutions could be applied. Two devices able to act on the tool electrode were proposed. One of the solution proposes the use of an electromagnetic subsystems, while the second solution is based on the use of a subassembly electric motor-gear box [13]. A novel compound machining of titanium alloy (Ti6Al4V) by super high speed Electrical Discharge Machining (EDM) milling and arc machining were proposed. The power supply consisted of a pulse generator and a DC power source which were isolated from each other. A rotating pipe graphite electrode was connected to the negative pole of the power supply. The plasma channel was able to deionize, and maximum Material Removal Rate (MRR) reached 21,494 $\mathrm{mm}^{3} / \mathrm{min}$ with a Relative Electrode Wear Ratio (REWR) of $1.7 \%$ because of high current and efficient flushing. Compared with traditional EDM, the compound machining achieved a significantly higher MRR but a similar REWR. To investigate the characteristics of the compound machining, the effects of electrode polarity, peak voltage, peak current, and flushing pressure on the performance of the process, including its MRR, REWR and Radius of Overcut (ROC), were determined. In addition, scanning electron microscopy, X-ray diffraction, and micro hardness analysis were conducted. Result shows that the proposed method can machine difficultto-machine materials efficiently [14]. The heat source diameter of single pulse discharge in electrical discharge machining was described. To observe the discharge plasma, $\mathrm{SiC}$ and $\mathrm{Ga}_{2} \mathrm{O}_{3}$ single crystals were used as the electrode material since they are optically transparent and electrically conductive. It was found that plasma diameter expands within a few microseconds after dielectric breakdown and the plasma diameter is much larger than the discharge crater. From the measured diameter of the crater, the heat source diameter was obtained by solving the inverse problem of heat conduction analysis, and it was found that the heat source diameter is smaller than the plasma diameter but larger than the crater diameter [15].

\section{EXPERIMENTAL WORK}

The experiments were performed on CONCORD DK7720C four axes CNC WED machine. The basic parts of the WED machine consist of a wire electrode, a work table, a servo control system, a power supply and dielectric supply system as shown in Figure 1 and Figure 2. The CONCORD DK7720C allows the operator to choose input parameters according to the material and height of the work piece. The WED machine has several special features. Unlike other WED machines, it uses the reusable wire technology. i.e., wire can't be thrown out once used; instead it is reused adopting the relooping wire technology. The experimental set-up for the data acquisition is illustrated in the Figure 3. The WEDM process generally consists of several stages, a rough cut phase, a rough cut with finishing stage, and a finishing stage. But in this
WED machine only one pass is used. Figure 4 shows the flow chart for entire process. The gap between wire and work piece is $0.02 \mathrm{~mm}$ and is constantly maintained by a computer controlled positioning system. By measuring the diameter of wire at various positions along length of the wire, wear was calculated. Molybdenum wire having diameter of $0.18 \mathrm{~mm}$ was used as an electrode.

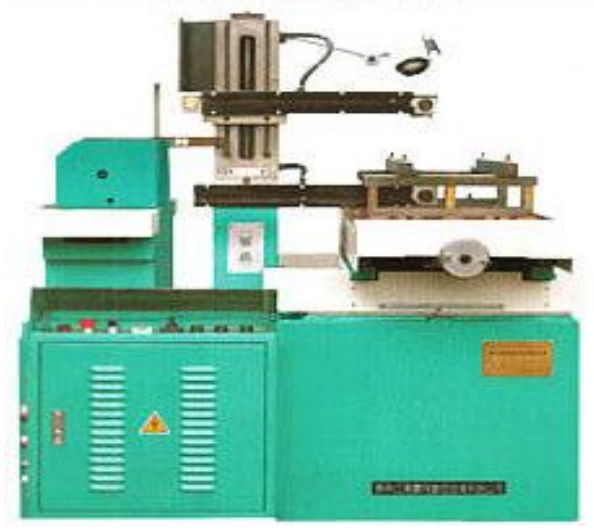

Figure 1: Wire Cut EDM Machine

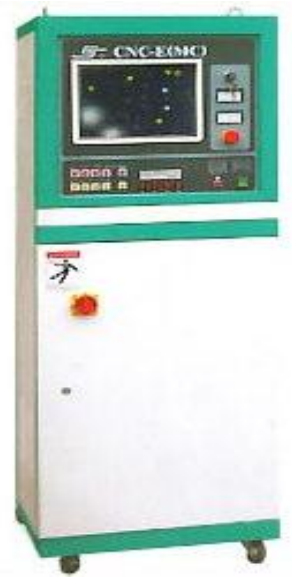

Figure 2: Controller used in $\mathrm{CNC}$

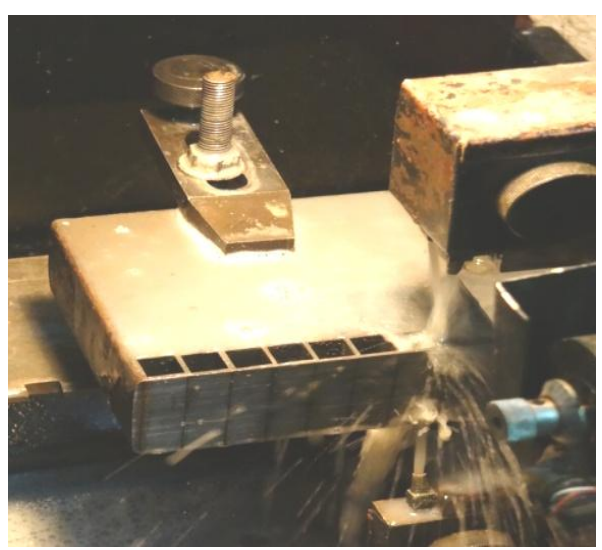

Figure 3: Experimental Set-up during Machining 


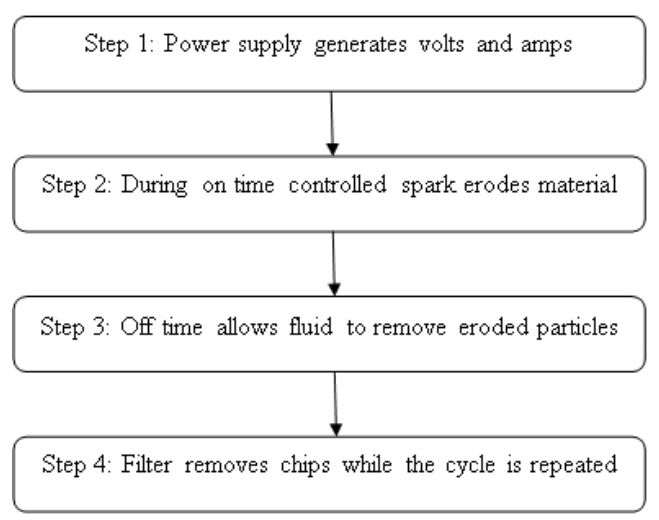

Figure 4: Flow Chart for EDM Process

The control factors and fixed parameters selected are as listed in Table 1. The control factors were chosen based on review of literature. In this study, five machining parameters were used as control factors and each parameter was designed to have four levels denoted I, II, III and IV as shown in Table 1. Table 2 shows the experimental design using Taguchi's L' ${ }_{16}$ orthogonal array.

Table 1: Machining Settings Used in Experiments

\begin{tabular}{|c|c|c|c|c|c|}
\hline \multicolumn{2}{|c|}{} & \multicolumn{4}{|c|}{ Level } \\
\hline \multicolumn{2}{|c|}{ Control Factors } & I & II & III & IV \\
\hline A & Pulse-on & 16 & 20 & 24 & 28 \\
\hline B & Pulse-off & 4 & 6 & 8 & 10 \\
\hline C & Current & 3 & 4 & 5 & 6 \\
\hline D & Bed speed & 20 & 25 & 30 & 35 \\
\hline
\end{tabular}

Table 2: Experimental Design using L' ${ }_{16}$ Orthogonal Array

\begin{tabular}{|c|c|c|c|c|}
\hline Run & $\begin{array}{c}\text { P-on } \\
(\mu \mathrm{s})\end{array}$ & $\begin{array}{c}\text { P-off } \\
(\mu \mathrm{s})\end{array}$ & $\begin{array}{c}\text { Current } \\
(\mathrm{A})\end{array}$ & $\begin{array}{c}\text { Bed Speed } \\
(\mu \mathrm{m} / \mathrm{s})\end{array}$ \\
\hline 1 & 16 & 4 & 3 & 20 \\
\hline 2 & 16 & 6 & 4 & 25 \\
\hline 3 & 16 & 8 & 5 & 30 \\
\hline 4 & 16 & 10 & 6 & 35 \\
\hline 5 & 20 & 4 & 4 & 30 \\
\hline 6 & 20 & 6 & 3 & 35 \\
\hline 7 & 20 & 8 & 6 & 20 \\
\hline 8 & 20 & 10 & 5 & 25 \\
\hline 9 & 24 & 4 & 5 & 35 \\
\hline 10 & 24 & 6 & 6 & 30 \\
\hline 11 & 24 & 8 & 3 & 25 \\
\hline 12 & 24 & 10 & 4 & 20 \\
\hline 13 & 28 & 4 & 6 & 25 \\
\hline 14 & 28 & 6 & 5 & 20 \\
\hline 15 & 28 & 8 & 4 & 35 \\
\hline 16 & 28 & 10 & 3 & 30 \\
\hline
\end{tabular}

\section{RESULTS AND DISCUSSIONS}

\section{A. Multiple Regression Analysis}

The objective of multiple regression analysis is to construct a model that explains as much as possible, the variability in a dependent variable, using several independent variables. The model fit is usually a linear model, though some timer nonlinear models such as log-linear models are also constructed. When the model constructed is a linear model, the population regression equation is

$$
Y_{i}=\alpha+\beta_{1} X_{1 i}+\ldots \ldots \ldots \ldots \ldots+\beta_{m} X_{m i}+e_{i}
$$

Where $Y_{i}$ is the dependent variable and $X_{1 i} \ldots \ldots \ldots . . . X_{m i}$ are the independent variables for $i^{\text {th }}$ data point and $e_{i}$ is the error term. Error term is assumed to have zero mean. The coefficients $\alpha, \beta_{1}, \ldots \ldots \ldots \mathrm{m}$ are not known and estimates of these values, designated as $a, b_{1} \ldots \ldots b_{m}$ have to be determined from the sampled data. For this least squares estimation is used, which consists of minimizing with respect to each of the co-efficients $a, b_{1} \ldots b_{m}$.

$$
S S=\sum_{i=1}^{n} e_{i}^{2}=\sum_{i=1}^{n} \mathbf{Q}_{i}-a-b_{i} X_{1 i} \ldots \ldots \ldots \ldots . . . b_{m} X_{m i} \text {, }
$$

This will give $k+1$ equations from which $a, b_{1} \ldots . . b_{m}$. can be obtained. These least squared estimates are the best linear unbiased estimates and hence gives the best linear unbiased estimate of the dependent variable.

$$
Y=a+b_{1} X_{1}+b_{2} X_{2}+\ldots \ldots \ldots \ldots+b_{m} X_{m}
$$
is,

The obtained regression model to estimate wear for EN-8

$W=2.25 e-3 \times A+9.87 e-4 \times B-3.25 e-4 \times C-5.5 e-5$

$x D-3.85 e-2$

The obtained regression model to estimate wear for EN19 is,

$W=2.01 e-3 \times A+1 e-3 \times B-3 e-4 \times C-7.3 e-36 \times D$ $-3.52 e-2$

Table 3 shows the process parameters used for machining EN-8 and EN-19 material based on L' ${ }_{16}$ orthogonal arrays, by considering the same values of pulse-on, pulse-off, current and bed speed as shown in Table 2, the time taken for machining, measured electrode wear using universal measuring machine and estimated wear by MRA

Table 3: Measured \& Estimated Wear for EN-8 and EN-19 Materials by MRA

\begin{tabular}{|c|c|c|c|c|}
\hline \multirow{2}{*}{ Run } & $\begin{array}{c}\text { Measured } \\
\text { Wear }(\mu \mathrm{m})\end{array}$ & $\begin{array}{c}\text { Predicted } \\
\text { Wear }(\mu \mathrm{m})\end{array}$ & $\begin{array}{c}\text { Measured } \\
\text { Wear }(\mu \mathrm{m})\end{array}$ & $\begin{array}{c}\text { Predicted } \\
\text { Wear }(\mu \mathrm{m})\end{array}$ \\
\cline { 2 - 5 } & \multicolumn{2}{|c|}{ EN-8 } & \multicolumn{2}{c|}{ EN-19 } \\
\hline 1 & 2 & 1.3625 & 2 & 1.85 \\
\hline 2 & 3 & 3.3875 & 5 & 4.15 \\
\hline 3 & 5 & 5.4125 & 7 & 6.45 \\
\hline 4 & 8 & 7.4375 & 9 & 8.75 \\
\hline 5 & 10 & 10.1625 & 10 & 10.2 \\
\hline 6 & 11 & 11.5375 & 11 & 11.9 \\
\hline 7 & 14 & 15.3125 & 14 & 14.8 \\
\hline 8 & 17 & 16.6875 & 16 & 16.5 \\
\hline 9 & 19 & 19.2375 & 18 & 18.55 \\
\hline 10 & 23 & 21.8125 & 21 & 20.85 \\
\hline 11 & 24 & 23.0875 & 22 & 21.95 \\
\hline 12 & 26 & 25.6625 & 24 & 24.25 \\
\hline 13 & 29 & 29.1375 & 27 & 26.9 \\
\hline 14 & 31 & 31.0625 & 29 & 28.6 \\
\hline 15 & 32 & 31.8875 & 31 & 30.3 \\
\hline 16 & 33 & 33.8125 & 32 & 32 \\
\hline
\end{tabular}

The estimated wear is correlating well with the measured one using multiple regression analysis. This can be seen in Figure 5 and Figure 6 for EN-8 and EN-19 materials. 


\section{B. Group Method Data Handling Technique}

One of the widely used methods for empirical analysis of data and model building is the multiple regressions. One of the major problems associated with use of regression has been the need to specify functional formulation. It would be preferable in such cases to use the data to determine both the nature of function and parameters of the function. This is the motivation for the development of self-organizing methods in modeling, GMDH is one such method. Data with the largest variance is put in the training set. The variance for $\mathrm{i}^{\text {th }}$ data point is given by

$$
D_{i}^{2}=\sum_{i=1}^{m}\left(X_{i j}-X_{j}\right)^{2} / \sigma_{j}^{2}
$$

Where, $D_{i}=$ measure of variance for $i^{\text {th }}$ data point, $\sigma_{j}=$ variance for $\mathrm{j}^{\text {th }}$ input variable, $\mathrm{X}_{\mathrm{j}}=$ mean for $\mathrm{j}^{\text {th }}$ variable and

$$
\sigma_{j}^{2}=(1 / n) \sum_{i=1}^{n}\left(X_{i j}-X_{j}\right)^{2}
$$

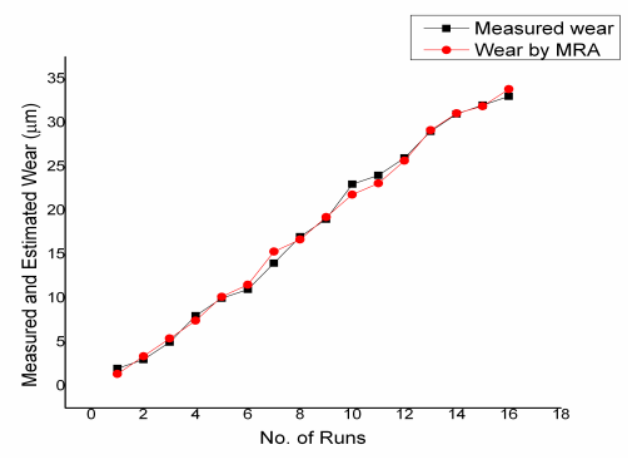

Figure 5: Predicted Wear Correlated and Compared to the Measured Wear for EN-8

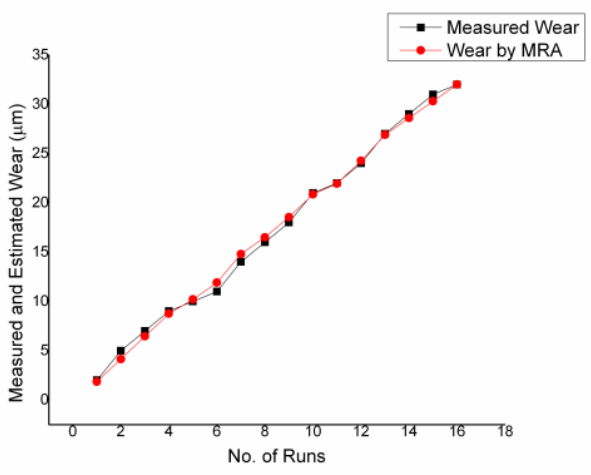

Figure 6: Predicted Wear Correlated and Compared to the Measured Wear for EN-19

Different models were obtained for 50\%, $62.5 \%$ and $75 \%$ of total data in the training set. The best model was selected from these. Number of variables selected at each layer will be taken as a fixed number or a constantly increasing number (usually given as fractional increase in number of independent variables present in the previous level). In this work, a fixed number, equal to the number of input variables, was taken. This was done to simplify the computational requirements.
Figure 7 to Figure 9 shows Level-1 GMDH estimates of electrode wear from various criteria viz., RMS, unbiased and combined, for $50 \%, 62.5 \%$ and $75 \%$ of data in training set for EN-8 material.

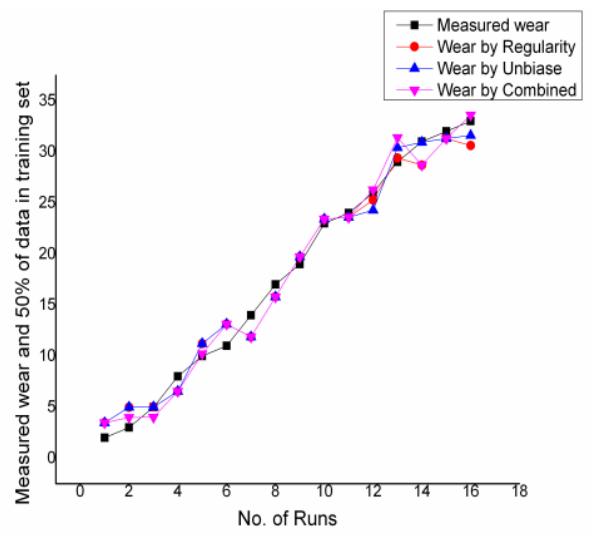

Figure 7: Electrode Wear for 50\% of Data in Training Set for EN-8

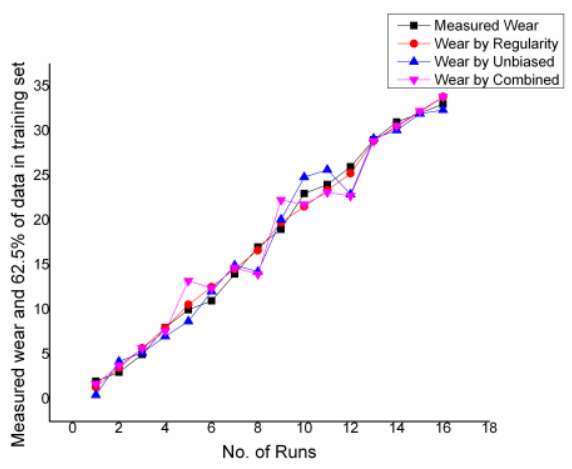

Figure 8: Electrode Wear for $62.5 \%$ of Data in Training Set for EN-8

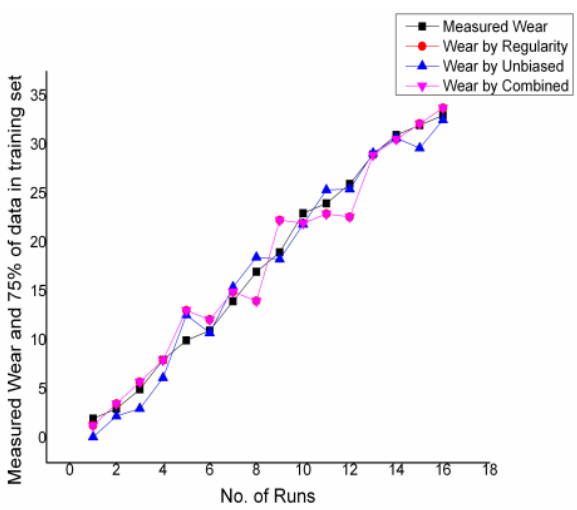

Figure 9: Electrode Wear for $75 \%$ of Data in Training Set for EN-8

Referring to the Figure 7 to Figure 9, it is observed that the electrode wear estimates obtained by RMS criterion with $62.5 \%$ of training set correlates well with the measured electrode wear. Estimates from $50 \%$ and $75 \%$ of data in training set give poor results for EN-8 material. 
Figure 10 to Figure 12 shows Level-1 GMDH estimates of electrode wear from various criteria viz., RMS, unbiased and combined, for $50 \%, 62.5 \%$ and $75 \%$ of data in training set for EN-19 material.

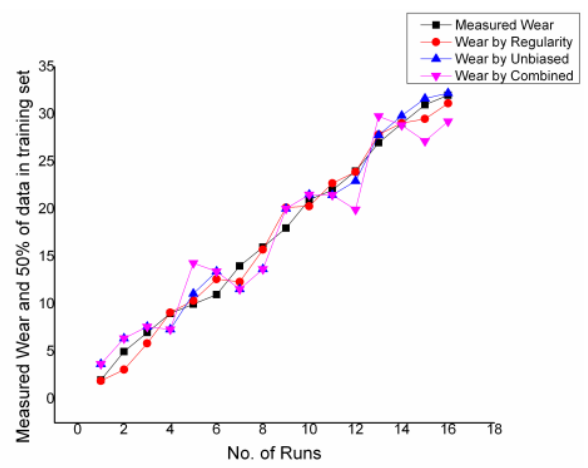

Figure 10: Electrode Wear for 50\% of Data in Training Set for EN-19

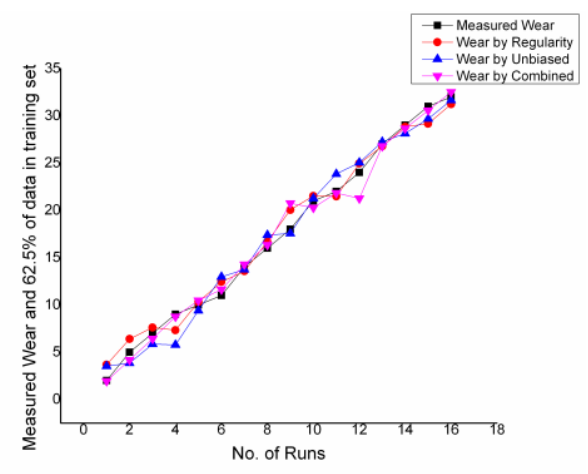

Figure 11: Electrode Wear for $62.5 \%$ of Data in Training set for EN-19

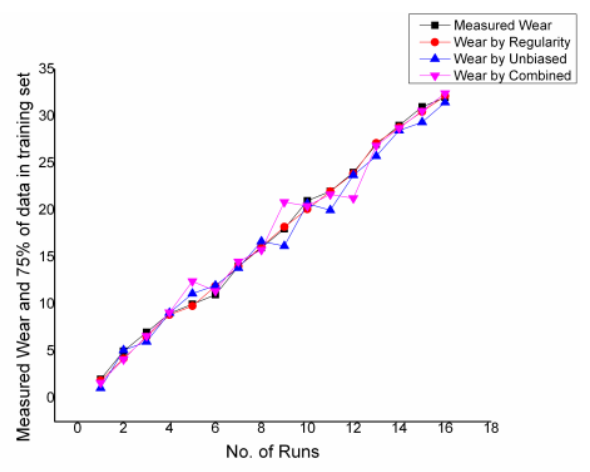

Figure 12: Electrode wear for $75 \%$ of data in training Set for $\mathrm{EN}-19$

Referring to the Figure 10 to Figure 12, it is observed that the electrode wear estimates obtained by RMS criterion with $62.5 \%$ and $75 \%$ of data in training set correlates well with the measured electrode wear. Estimates from $50 \%$ of data in training set give poor results for EN-19 material.

RMS criterion has good predictive power but is sensitive to noise. Unbiased criterion selects models that are insensitive to data from which it is built and hence gives good noise immunity but may not have good predictive power. Combined criterion is a combination of both RMS \& combined.

\section{Comparison of MRA and GMDH}

Multiple regression analysis and GMDH have been used to estimate electrode wear in WEDM. Both the methods have been found to estimate electrode wear well as discussed in the above sections. From the standpoint of identifying a better method among the two, the results from both the methods are compared. Regularity criterion of GMDH with $50 \%$ of data in the training set gave better estimation than the other criteria and percentage of data. Hence, it is considered for the comparison. Among these, regularity criterion of GMDH gives less standard error compare to MRA and GMDH gives better estimation than multiple regressions.

\section{CONCLUSION}

MRA and GMDH techniques were successfully used for predicting the response variables. It was found that, each control factors are affecting the response variables to different extent. We have also seen that multiple regression analysis is a preferred tool for estimating electrode wear for EN-8 and EN19 material. Comparing the electrode wear for EN-19 gave better result than EN-8. Three different criterion functions of GMDH viz., Regularity (RMS), Unbiased and Combined have been tried for electrode wear estimation for EN-8 and EN-19. The results from the present work show that the regularity criterion function provides good estimation than the other two functions. Different models of GMDH were built by varying the number of data in the training set to $50 \%, 62.5 \%$ and $75 \%$ of the total data. It was found that the least error of estimation and best-fit was found for $62.5 \%$ of data in training set for EN-8 material and $62.5 \%$ and $75 \%$ of data in training set for EN-19 material. Comparison of the two theoretical methods for estimation of electrode wear, it was found that, Regularity criterion function of GMDH has an edge over MRA method. RMS criterion function gave better estimation than MRA.

\section{REFERENCES}

[1] Ki Young Song, Do Kwan Chung, Min Soo Park and Chong Nam Chu, "EDM turning using a strip electrode", Journal of Materials Processing Technology, 213, 9, 1495-1500, 2013.

[2] E. Weingärtner, K. Wegener and F. Kuster, "Influence of workpiece circumferential speed in wire electrical discharge machining", The Seventeenth CIRP Conference on Electro Physical and Chemical Machining (ISEM), Procedia, CIRP, 6, 239-244, 2013.

[3] L. Li, Y.B. Guo, X.T. Wei and W. Li, "Surface integrity characteristics in wire-EDM of inconel 718 at different discharge energy", Seventeenth International Symposium on Electromachining, Procedia, CIRP, 6, 221226, 2013.

[4] K.Y. Song, D.K. Chung, M.S. Park and C.N. Chu, "Development of strip EDM", The Seventeenth CIRP Conference on Electro Physical and Chemical Machining (ISEM), Procedia, CIRP, 6, 53-57, 2013.

[5] M-T. Yan, G-R. Fang, Y-T. Liu and J-R. Li, "Fabrication of polycrystalline diamond wheels by micro wire-EDM using a novel pulse generator", The Seventeenth CIRP Conference on Electro Physical and Chemical Machining (ISEM), Procedia, CIRP, 6, 204-209, 2013.

[6] Y. Zhao, M. Kunieda and K. Abe, "Experimental investigations into EDM behaviors of single crystal silicon carbide", The Seventeenth CIRP Conference on Electro Physical and Chemical Machining (ISEM), Procedia, CIRP, 6, 135-139, 2013.

[7] H. Gotoh, T. Tani, M. Okada, A. Goto, T. Masuzawa and N. Mohri, "Wire electrical discharge milling using a wire guide with reciprocating 
rotation", The Seventeenth CIRP Conference on Electro Physical and Chemical Machining (ISEM), Procedia, CIRP, 6, 200-203, 2013.

[8] Tong Hao, Li Yong, Zhang Long and Li Baoquan, "Mechanism design and process control of micro EDM for drilling spray holes of diesel injector nozzles", Precision Engineering, 37, 213-221, 2013.

[9] Jian-Zhong Li, Lu Xiao, Hui Wang, Hui-Lan Yu and Zu-Yuan Yu, "Tool wear compensation in 3D micro EDM based on the scanned area", Precision Engineering, 37, 3, 753-757, 2013.

[10] U. Maradia, M. Scuderi, R. Knaak, M. Boccadoro, I. Beltrami, J. Stirnimann and K.Wegener, "Super-finished surfaces using meso-micro EDM", The Seventeenth CIRP Conference on Electro Physical and Chemical Machining (ISEM), Procedia, CIRP, 6, 157-163, 2013.

[11] Kapil Gupta and Neelesh Kumar Jain, "Analysis and Optimization of Micro-Geometry of Miniature Spur Gears Manufactured by Wire Electric Discharge Machining", Precision Engineering, (Accepted Manuscript), 2014.

[12] T. Muthuramalingama and B. Mohan, "A review on influence of electrical process parameters in EDM process", archives of civil and mechanical engineering, (Article in press), 2014.

[13] Oana Dodun, LaurențiuSlătineanu and Lorelei Gherman, "Improving the WEDM process acting on the tool electrode", The 7th International Conference Interdisciplinary in Engineering (INTER-ENG 2013), Procedia Technology, 12, 427-432, 2014.

[14] Fei Wang, Yonghong Liu, Yanzhen Zhang, Zemin Tang, Renjie Ji and Chao Zheng, "Compound machining of titanium alloy by super high speed EDM milling and arc machining", Journal of Materials Processing Technology, 214, 531-538, 2014.

[15] Tomoo Kitamura and Masanori Kunieda, "Clarification of EDM gap phenomena using transparent electrodes", CIRP Annals - Manufacturing Technology, (Article in press), 2014.

G.Ugrasen, presently working as Assistant Professor, in the Department of Mechanical Engineering, BMS College of Engineering, Bangalore 560019 , Karnataka, India. Has 9 years of Teaching and Research experience.

E-mail: ugrasen.g@gmail.com

H.V.Ravindra, presently working as Professor, in the Department of Mechanical Engineering, PES College of Engineering, Mandya-571 401, Karnataka, India. Has more than 30 years of Teaching and Research experience.

E-mail: mailhovera@yahoo.com

G.V. Naveen Prakash, presently working as Professor, Department of Mechanical Engineering, Vidya Vardhaka College of Engineering, Mysore570 002, Karnataka, India. Has more than 18 years of Teaching and Research experience.

E-mail: npgvi@yahoo.co.in

D.L.Vinay, Assistant Professor, Department of Mechanical Engineering, Dayananda Sagar Academy of Technology \& Management, Bangalore-560 082, Karnataka, India. Has 1 year of Teaching and Research experience.

E-mail: vinaydl.viny@gmail.com 